\title{
Guinea Pigs with Inherited Deficiencies of Complement Components C2 or C4 Have Characteristics of Immune Complex Disease
}

\author{
Erik C. Böttger, Thomas Hoffmann, Uirich Hadding, and Dieter Bitter-Suermann \\ Institute of Medical Microbiology, Johannes Gutenberg University, 6500 Mainz, Federal Republic of Germany
}

\begin{abstract}
Guinea pigs genetically deficient in the second (C2) or fourth component of complement (C4) generally appear healthy in contrast to humans with a $\mathrm{C} 2$ or $\mathrm{C} 4$ deficiency. However, upon investigation of these genetic deficiencies in guinea pigs for signs of dysregulation in the humoral immune system and especially autoantibodies, many complement-deficient guinea pigs $(>50 \%)$ had elevated levels of serum IgM and higher concentrations of anti-hapten (dinitrophenyl) antibodies as signs of polyclonally stimulated antibody synthesis. In addition, a significant number of the complement-deficient animals, on average $30 \%$, had IgM rheumatoid factors in their sera compared with $<1 \%$ of the normal animals. These observations, therefore, indicate that guinea pigs, genetically deficient in $\mathrm{C2}$ or $\mathrm{C4}$, show characteristics of immune complex disease in general.
\end{abstract}

\section{Introduction}

Numerous reports have established that humans, genetically deficient in components of the classical pathway of complement (C), ${ }^{1}$ are suspectible to immune complex diseases in general and the juvenile type of systemic lupus erythematosus (SLE) in particular (for reviews, 1-3). Generally, patients with SLE have multiple autoantibodies, e.g., against DNA or serum proteins (4).

In contrast, guinea pigs genetically deficient in the second (C2D-GP) or fourth component of C (C4D-GP) appear healthy $(5,6)$, even though an impaired humoral immune response was previously shown for both C4D-GP $(5,7)$ and C2D-GP (5). Although these animals have no overt clinical symptoms, we tested the sera of these genetically C-deficient guinea pigs for serologic abnormalities in order to determine whether they are predisposed to autoimmunity. In particular, we tested for circulating immune complexes, antibodies against complement proteins, and socalled rheumatoid factors, which is a collective term for immunoglobulins of the IgM or IgG class specific for antigenetic determinants on homologous or heterologous aggregated IgG $(6,8-12)$. We also determined levels of serum $\operatorname{IgM}, \operatorname{IgG}$, and

Received for publication 4 December 1985 and in revised form 26 March 1986.

1. Abbreviations used in this paper: AGG, heat-aggregated guinea pig gamma-globulin; C, complement; C2D-GP, guinea pigs deficient in the second component of complement; C4D-GP, guinea pigs deficient in the fourth component of complement; DNP, dinitrophenyl; ELISA, enzyme-linked immunosorbent assay; MHC, major histocompatibility complex; RF, rheumatoid factor; SLE, systemic lupus erythematosus.

J. Clin. Invest.

(c) The American Society for Clinical Investigation, Inc.

0021-9738/86/09/0689/07 \$1.00

Volume 78, September 1986, 689-695 antibodies against the hapten dinitrophenyl (DNP), in that a common feature of human SLE and murine SLE models is hypergammaglobulinemia and spontaneously elevated levels of various anti-hapten antibodies $(13,14)$.

Our results suggest, that these C-deficient guinea pigs may serve as an experimental model to study the contribution and pathogenetic role of $\mathrm{C}$ deficiency during the development and sustaining of auto-immune diseases, especially for the role of these deficiencies in SLE in humans.

\section{Methods}

Experimental animals. C4D-GP (National Institutes of Health origin 1974) and C2D-GP (15) came from our in-house breeding colony. Both strains are partially inbred up to the tenth generation. The C-deficiency state was confirmed by negative results in $\mathrm{C} 2$ or $\mathrm{C} 4$ hemolytic assays $(15,16)$. Guinea pigs of inbred strains 2 and 13 served as controls. The strain 13 is major histocompatibility complex (MHC) identical to the C4-deficient strain (17). Healthy animals of both sexes, at least 6-9 mo old were used for the studies and the different strains were comparable in terms of age and sex. All animals were held in closed colonies and received the same standardized diet. In addition, C-deficient guinea pigs of both sexes between $2 \mathrm{wk}$ and 5 mo of age were examined for a possible age-dependent development of the investigated parameter.

Blood was obtained by cardiac puncture, allowed to clot for $2 \mathrm{~h}$ at room temperature, and then centrifuged. Serum was stored in small aliquots at $-70^{\circ} \mathrm{C}$. All cardiac punctures were done under anesthesia ( 5 $\mathrm{ml}$ of $50 \mathrm{mg} / \mathrm{ml}$ Ketanest [Parke-Davis, Munich, Federal Republic of Germany] and $1 \mathrm{ml}$ atropine $0.0005 \%$ [Fresenius, Oberursel, Federal Republic of Germany] $-0.6 \mathrm{ml}$ i.m. per animal).

Solid-phase enzyme-linked immunosorbent assay (ELISA) for circulating immune complexes. A solid-phase $\mathrm{C} 3$ immunoassay was used as described previously (18) with minor modifications to detect circulating immune complexes bearing C3b. A mouse monoclonal antibody of $\gamma 1$ subclass with a weak affinity for native guinea pig $\mathrm{C} 3$ but a strong affinity for its fragments C3b and C3c was used (19). U-shaped wells of flexible polyvinyl chloride microtiter plates (Dynatech Germany, Nürtingen, Federal Republic of Germany) were coated with $20 \mu$ lof anti-C3 (purified by ammonium sulfate precipitation) in $0.1 \mathrm{M} \mathrm{NaHCO}_{3}, \mathrm{pH} 9.6(15 \mu \mathrm{g} /$ $\mathrm{ml}$, protein concentration was determined according [20] to Bradford) overnight at $4^{\circ} \mathrm{C}$. Plates were then washed with phosphate-buffered saline (PBS) and $200 \mu \mathrm{l}$ of PBS-bovine serum albumin (BSA) was added to each well for $1 \mathrm{~h}$ at $4^{\circ} \mathrm{C}$ to cover unreacted sites. Then $50 \mu$ l of either standard (see below) or serum diluted $1 / 21$ in PBS-BSA-EDTA $0.1 \mathrm{M}$, pH 7.2, was added for $1 \mathrm{~h}$ at room temperature. After washing with PBS containing $0.05 \%$ Tween, $20 \mu$ l of peroxidase-labeled rabbit anti-guinea pig Ig (Dakopatts, Hamburg, Federal Republic of Germany) 1:500 in PBS-BSA was added and developed using 2,2'-azino-di(-3-ethylbenzthiazoline sulfonate [5]) (Boehringer, Mannheim, Federal Republic of Germany) as substrate. Optical densities (OD) were read in an automatic ELISA reader at $414 \mathrm{~nm}$ (Flow Laboratories, Meckenheim, Federal Republic of Germany).

The standards were prepared by adding heat-aggregated $(20 \mathrm{~min}$, $63^{\circ} \mathrm{C}$ ) guinea pig gamma-globulin (AGG) to fresh guinea pig serum and incubating for $30 \mathrm{~min}$ at $37^{\circ} \mathrm{C}$. The binding of AGG to the anti-C3coated wells was proportional to the amount of AGG, whereas the same gamma-globulin preparation, not heated or aggregated, showed no reaction. This indicated that it was $\mathrm{C} 3$-previously activated and bound 
by AGG-which was detected by the antibody, and monomeric IgG did not interfere with the assay. A sensitivity of $2-4 \mu \mathrm{g} A G G / \mathrm{ml}$ was consistently obtained.

Detection of rheumatoid factors. Guinea pig antibodies directed against heterologous mouse gamma-globulins were detected by solid-phase ELISA. Different subclasses of mouse monoclonal antibodies were used as antigens to detect subclass-specific rheumatoid factors. These monoclonal antibodies were directed against antigens not present in animal sera, i.e., bacterial antigens. In particular, we used: monoclonal $\gamma 1$, specificity for antiplasmid-encoded outer membrane protein of Escherichia coli (anti-TraTp) (21); monoclonal $\gamma 3$, specificity anti-K 12 lipopolysaccharide (unpublished); and monoclonal $\gamma 2 \mathrm{a}$, specificity anti-TraTp (21).

The $\gamma 1$ monoclonal antibody was purified by $40 \%$ ammonium sulfate precipitation, the $\gamma 2 \mathrm{a}$ and $\gamma 3$ monoclonals by Protein A-Sepharose (Deutsche Pharmacia, Freiburg, Federal Republic of Germany) as described (22). Each antibody was bound to U-shaped wells of flexible microtiter plates (Dynatech Germany) in duplicate overnight at $4^{\circ} \mathrm{C}$ using $20 \mu \mathrm{l}$ of a $15 \mu \mathrm{g} / \mathrm{ml}$ solution of protein in $0.1 \mathrm{M} \mathrm{NaHCO}_{3}, \mathrm{pH}$ 9.6. The remaining steps were carried out as described above.

A similar solid-phase immunoassay was performed to assess the serum levels of guinea pig IgM-rheumatoid factor (RF) for homologous IgG. Guinea pig $\gamma 2$ was prepared according to Furuichi et al. (23) and further purified by preparative isoelectric focusing in granulated gels (Sephadex G-25). A solution of $30 \mu \mathrm{g} / \mathrm{ml}$ covered the microtiter plates. IgM-RF were detected by polyclonal sheep anti-guinea pig IgM (Nordic, Tilburg, The Netherlands) diluted 1:1,000 in PBS-BSA, and developed with peroxidase-labeled rabbit anti-sheep Ig (Dakopatts), 1:500 in PBS-BSA.

Solid-phase ELISA for antibodies to C3b or C3. Guinea pig C3 was prepared according to Burger et al. (19) and further purified by fast protein liquid chromatography over a column containing the anionic exchanger Mono Q (Deutsche Pharmacia). The elution buffer was $0.01 \mathrm{M}$ Tris$\mathrm{HCl}, \mathrm{pH} 8.5$, and an $\mathrm{NaCl}$ gradient ranged from 0.03 to $0.42 \mathrm{M} \mathrm{NaCl}$. The preparation, which eluted at $0.21 \mathrm{M} \mathrm{NaCl}$, had a protein content of $24 \mathrm{mg} / \mathrm{ml}$; it gave a single homogeneous line with the appropriate molecular weight $(180,000 \mathrm{~mol} w \mathrm{wt})$ when applied to an analytical SDSPAGE, and it was hemolytically active.

Guinea pig C3b was prepared according to Burger et al. (19) and further purified by fast protein liquid chromatography with the same procedure as described above for $\mathrm{C} 3$. The preparation, which eluted at $0.22 \mathrm{M} \mathrm{NaCl}$, had a protein content of $3 \mathrm{mg} / \mathrm{ml}$; it gave a single homogenous line on sodium dodecyl sulfate-polyacrylamide gel electrophoresis $(170,000 \mathrm{~mol} \mathrm{wt})$, and it was hemolytically inactive.

$20 \mu \mathrm{l}$ of $\mathrm{C} 3 \mathrm{~b}(40 \mu \mathrm{g} / \mathrm{ml})$ or C3 $(100 \mu \mathrm{g} / \mathrm{ml})$ in PBS was bound to Ushaped wells of flexible microtiter plates (Dynatech) overnight at $4^{\circ} \mathrm{C}$. The following steps were the same as described above, except serum was diluted in PBS-EDTA $0.01 \mathrm{M}, \mathrm{pH}$ 7.4. The reaction was developed with peroxidase-labeled rabbit anti-guinea pig Ig (Dakopatts). Inhibition studies were performed with different monoclonal mouse antibodies to guinea pig C3b (19). Monoclonal antibodies 101, 105, and 110 recognized C3, $\mathrm{C} 3 \mathrm{~b}$, and $\mathrm{C} 3 \mathrm{c}$, respectively, but not C3d.

Solid-phase immunoassay for IgM antibodies to DNP. Serum levels of IgM antibodies to DNP were assayed with an ELISA using DNPalbumin (Calbiochem, Frankfurt, Federal Republic of Germany) as antigen. $20 \mu \mathrm{l}$ of a $1 \mu \mathrm{g} / \mathrm{ml}$ solution in $0.1 \mathrm{M} \mathrm{NaHCO}_{3}, \mathrm{pH} \mathrm{9.6,} \mathrm{was} \mathrm{bound}$ to each well. The remaining steps were done as described above, except that a biotinylated mouse monoclonal anti-guinea pig IgM (1:100 in PBS-BSA) of the $\gamma 1$ subclass was used, (the latter was induced by immunization with the guinea pig B-cell leukemia line EN-L2C and kindly provided by Dr. R. Burger, Heidelberg, Federal Republic of Germany). We then developed with peroxidase-labeled streptavidin (Amersham Buchler, Braunschweig, Federal Republic of Germany) 1:1000 in PBS-BSA.

Quantitative determination of serum IgM and IgG. For determination of the serum IgM level, wells of microtiter plates were coated with the above described monoclonal mouse anti-guinea pig IgM $(20 \mu \mathrm{l} /$ well of a $15 \mu \mathrm{g} / \mathrm{ml}$ solution in $0.1 \mathrm{M} \mathrm{NaHCO}_{3} \mathrm{pH} 9.6$ ) overnight at $4^{\circ} \mathrm{C}$. Plates were then washed and coated with PBS-BSA. $20 \mu \mathrm{l}$ of either standard guinea pig IgM (Paesel, Frankfurt) or serum diluted 1:1,000 in PBS-BSA was added and developed with polyclonal sheep anti-GP IgM (Nordic) diluted 1:1,000 in PBS-BSA and peroxidase-labeled rabbit anti-sheep Ig (Dakopatts) diluted 1:500 in PBS-BSA.

Serum IgG levels, $\gamma 1$ and $\gamma 2$ subclass (24), were determined in a similar manner using affinity-purified goat anti-guinea pig IgG Fc (20 $\mu \mathrm{l} /$ well of a $10 \mu \mathrm{g} / \mathrm{ml}$ solution, Jackson Immuno Research, Avondale, PA), serum dilutions of 1:5,000 and peroxidase-labeled rabbit anti-guinea pig Ig 1:500 (Dakopatts). As internal standard we used the above described $\gamma 2$ preparation. In addition, the levels of serum IgG were analysed by radial immunodiffusion using goat anti-GP IgG and kindly performed by Dr. Baudner (Behring-Werke, Marburg, Federal Republic of Germany).

Statistical methods. Mean \pm 1 SD was calculated, and values above 2 SD were considered positive. Data were examined by Fisher's exact 2 $\times 2$ table test. $P$ values were given. For correlation analysis, logarithms of the data were used.

\section{Results}

Determination of serum IgM and IgG concentrations. Serum samples from strain 13 guinea pigs and strain 2 guinea pigs were analyzed for their IgM levels (Fig. 1). The mean value for these control animals was $706 \pm 292 \mu \mathrm{g} \mathrm{IgM/ml} \mathrm{(} \pm 1$ SD). Three control animals (3.7\%) had slightly elevated IgM levels above 2 SD $(1,320,1,340$, and $1,390 \mu \mathrm{g} / \mathrm{ml}$, respectively). In contrast, serum levels far exceeding 2 SD were obtained for the majority of the C-deficient animals: $59.7 \%$ of the C2D-GP and $88.2 \%$ of the C.4D-GP. $P$ values in every case were $<0.001$. Thus, even the mean serum IgM level of both C-deficient strains was elevated: $1,981 \pm 1,416 \mu \mathrm{g} / \mathrm{ml}$ for the C2D group and 2,424 $\pm 1,606 \mu \mathrm{g} / \mathrm{ml}$ for the C4D group.

Determination of serum IgG levels-in the ELISA system as well as in the radial immunodiffusion-revealed a remarkable variation even in the control animals. The same was true for

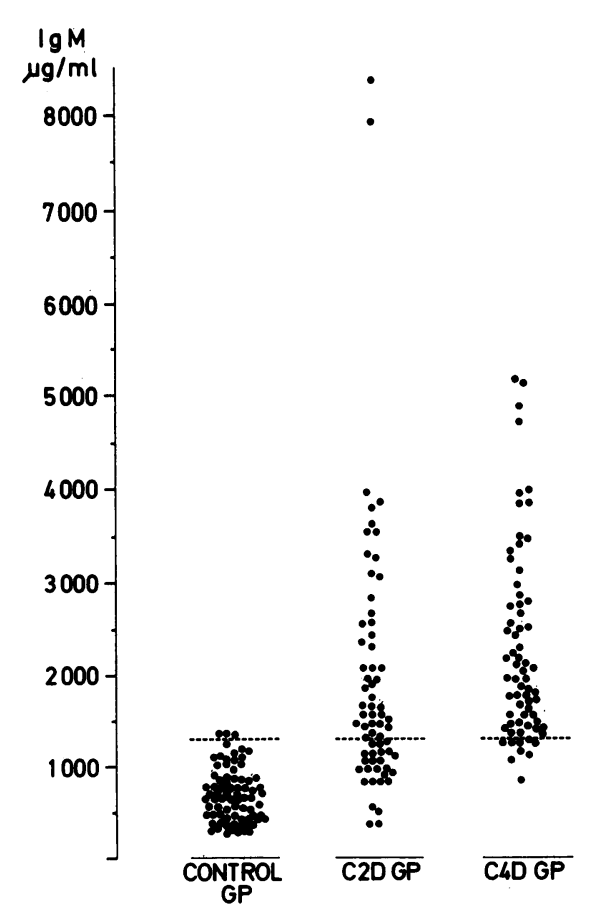

Figure 1. Serum IgM concentrations: control guinea pigs (GP) (n $=81 ; 48$ animals of strain 13 and 33 animals of strain 2), C2D-GP ( $n$ $=67)$, C4D-GP $(n=68)$. The dotted line indicates normal mean +2 SD. 


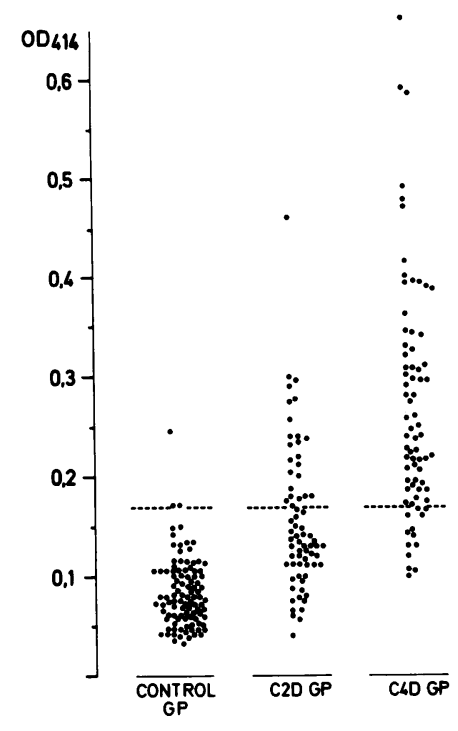

Figure 2. Detection of IgM antibodies to DNP in guinea pig (GP) sera: control GP $(n=91$; 58 animals of strain 13 and 33 animals of strain 2), C2D-GP $(n=67)$, C4D-GP $(n=71)$.

The dotted line indicates normal mean $+2 \mathrm{SD}$.

the C-deficient guinea pigs. The statistical analysis of the data gave no hint for elevations of this class of gamma-globulins for the C-deficient guinea pigs in comparison with the control animals (data not shown).

IgM antibodies to DNP. Serum samples were analyzed for IgM antibodies to DNP (Fig. 2). The mean value (expressed as OD) of the control animals was $92 \pm 40$. Three control guinea pigs $(3.3 \%$ ) had levels exceeding $2 \mathrm{SD}$, whereas $34.3 \%$ of the C2D-GP and $80.3 \%$ of the C4D-GP had elevated levels of IgM antibodies to DNP. These differences were highly significant $(P$ $<0.001$ ).

Antibodies against heterologous mouse gamma-globulins and rheumatoid factors in guinea pig sera. The normal concentration of guinea pig antibodies to heterologous mouse gamma-globulins of the $\gamma 2 \mathrm{a}, \gamma 3$, or $\gamma 1$ subclass was assessed by testing serum samples from 124 normal guinea pigs of two different strains.

Three control animals $(2.4 \%)$ had levels above 2 SD in the anti-mouse $\gamma 2 \mathrm{a}$ assay (Fig. $3 \mathrm{~A}$ ). In contrast, 12 of $138 \mathrm{C} 2 \mathrm{D}-\mathrm{GP}$ $(8.7 \%)$ had values exceeding 2 SD. Using Fisher's exact $2 \times 2$ table test, the difference compared with the control animals proved to be significant $(P=0.05)$. Likewise levels above $2 \mathrm{SD}$ were found in the C4D group: 12 of 130 animals (9.2\%); compared with the control animals, the difference was significant $(P$ $=0.04$ ). Using mouse $\gamma 3$ globulin as antigen (Fig. $3 B$ ), the sera of four control animals (3.2\%) exceeded 2 SD. Again a higher number of the C-deficient GP were positive $(=>2 \mathrm{SD})$ in this assay, i.e., 17 of the C2D-GP group (12.2\%) and 16 animals of the C4D-GP group (12.3\%). $P$ values in every case were $<0.005$. As in the anti- $\gamma 2 \mathrm{a}$ assay, those values above 2 SD were consistently higher in the C-deficient animals than in the control animals.

After testing the guinea pig sera for antibodies against mouse $\gamma$ 1-globulin (Fig. $3 C$ ), similar results were found. Two control sera $(1.6 \%)$ had levels above $2 \mathrm{SD}$, whereas this applied to 16

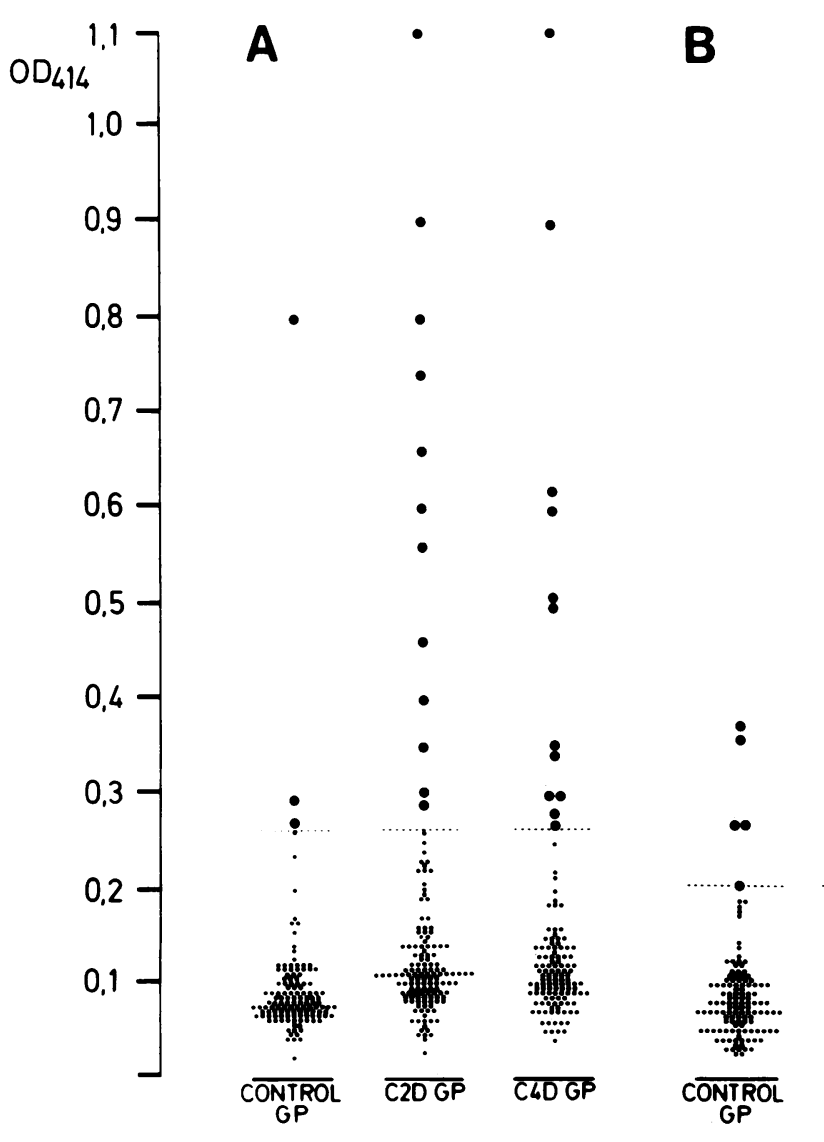

Figure 3. Titration of guinea pig (GP) antibodies to monoclonal mouse immunoglobulin by ELISA: (reactivity expressed as OD) control GP $(n=124 ; 91$ animals of strain 13 and 33 animals of strain 2$)$, C2D-GP $(n=138)$, C4D-GP $(n=130)$; each serum is represented by

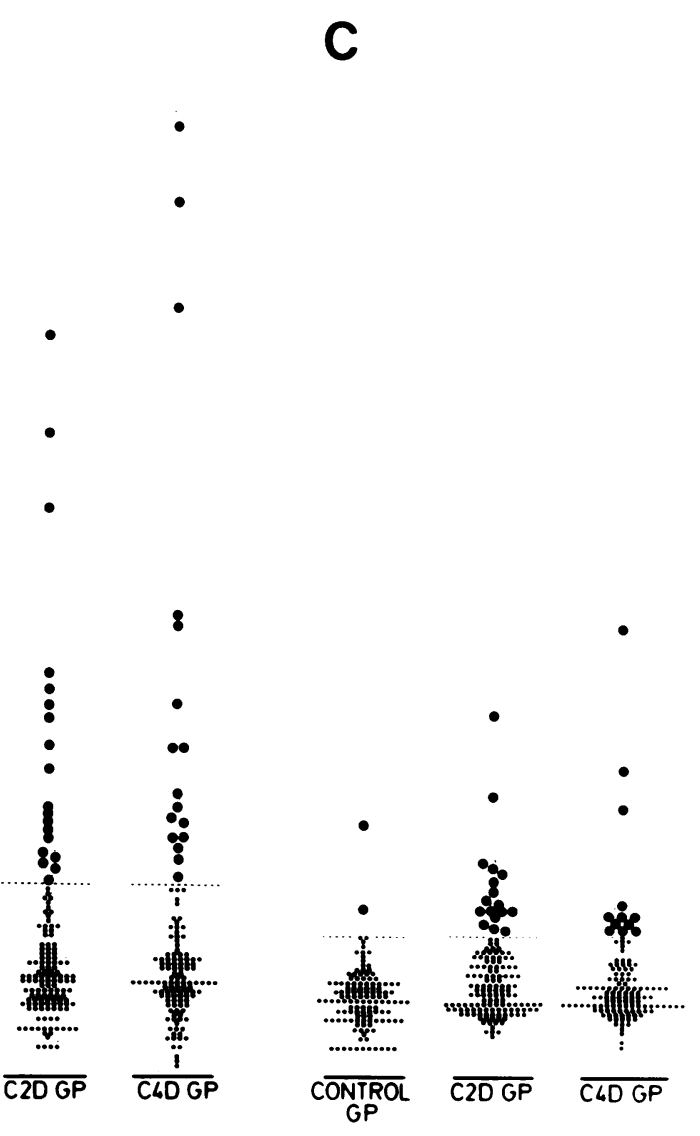

a single point; the dotted line indicates normal mean $+2 \operatorname{SD}(A)$ using mouse $\gamma 2 \mathrm{a}$ as antigen, $(B)$ using mouse $\gamma 3$ as antigen, $(C)$ using mouse $\gamma 1$ as antigen. 
C2D-GP (11.6\%) and 12 C4D-GP (9.2\%). $P$ values were $<0.01$ in every case.

To determine whether the $\mathrm{C}$-deficient guinea pigs have IgMRF recognizing homologous gamma-globulin, we tested reactivity against homologous guinea pig immunoglobulin, using purified guinea pig $\gamma 2$-globulins as antigen (Fig. 4). One control guinea pig $(0.84 \%)$ had levels exceeding $2 \mathrm{SD}$. In contrast 15 of 67 C2D-GP (22.4\%) and 27 of 71 C4D-GP (38.0\%) were positive in this assay. Using Fisher's exact $2 \times 2$ table test, these differences were highly significant $(P<0.001)$. Most C2D-GP and all C4DGP reactive against heterologous mouse $\gamma 2 \mathrm{a}$ had also IgM-RF recognizing homologous $\gamma 2(P$, Pearson chi-square $<0.001)$.

Circulating immune complexes in guinea pig sera. The results of the $\mathrm{C} 3$ assay (see Methods) for detecting immune complexes bearing $\mathrm{C} 3 \mathrm{~b}$ were hampered by the fact that guinea pig antibodies against mouse $\gamma 1$ globulins did interfere with this assay (the anti-C 3 is of $\gamma 1$ subclass). In fact, three of the four control animals (3.2\%), which had levels above $2 \mathrm{SD}$, were also reactive against a panel of four different $\gamma 1$ monoclonals, indicating that their positive reaction in the immune complex assay was probably due to anti- $\gamma 1$ antibodies. Comparably most of the 19 C2DGP (13.8\%) and 19 C4D-GP (14.6\%) positive in the immune complex assay also reacted with these different $\gamma 1$ monoclonals except two animals of each group, which reacted exclusively with the anti-C3 antibody for detection of immune complexes (data not given).

Antibodies against $C 3 b$. The mean value in the ELISA for antibodies to $C 3 \mathrm{~b}$ was $87 \pm 61(+1 \mathrm{SD})$, expressed in OD, for the control animals (data not shown). However, the difference between the $\mathrm{C}$-deficient and normal guinea pigs was not significant: six control guinea pigs (4.8\%), seven C2D-GP (5.1\%), and eight C4D-GP (6.15\%) had levels above $2 \mathrm{SD}$. None of these sera were reactive with native $\mathrm{C} 3$ in the ELISA (data not shown). Therefore reactivity against $\mathrm{C} 3 \mathrm{~b}$ may have been due to an antigenetic neodeterminant not shared by native $\mathrm{C} 3$.

One C2D-GP had exceedingly high antibody titers to C3b. We investigated this further with an inhibition ELISA: C3b was bound to the wells of a microtiter plate as described above. We then tried to block binding of the guinea pig autoantibody to $\mathrm{C} 3 \mathrm{~b}$ by preincubation of bound $\mathrm{C} 3 \mathrm{~b}$ with different mouse monoclonal antibodies to guinea pig $\mathrm{C} 3 \mathrm{~b}$ (all of $\gamma 1$ subclass). As shown in Fig. 5 constant, albeit weak, inhibition was seen with two of three anti-C $3 b$ monoclonal antibodies; this inhibition was slightly enhanced when adding both monoclonals together.

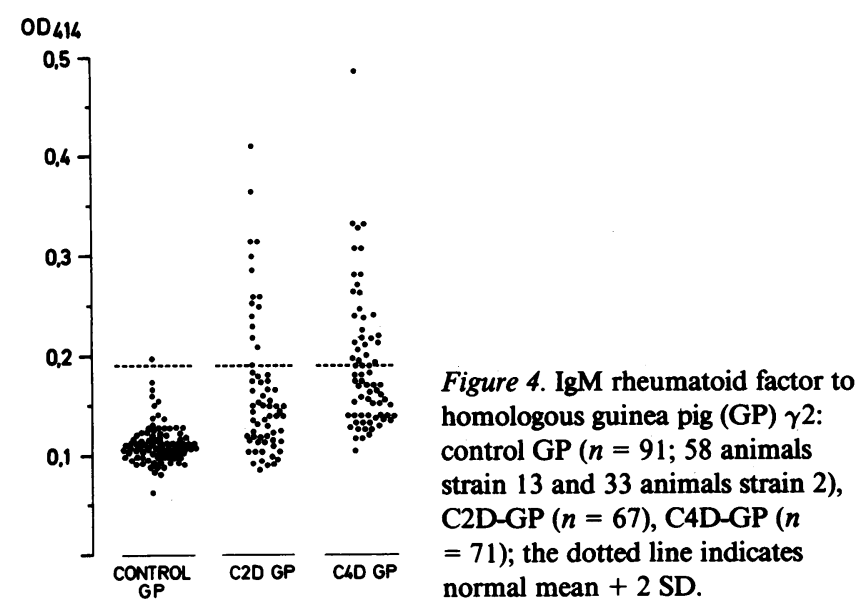

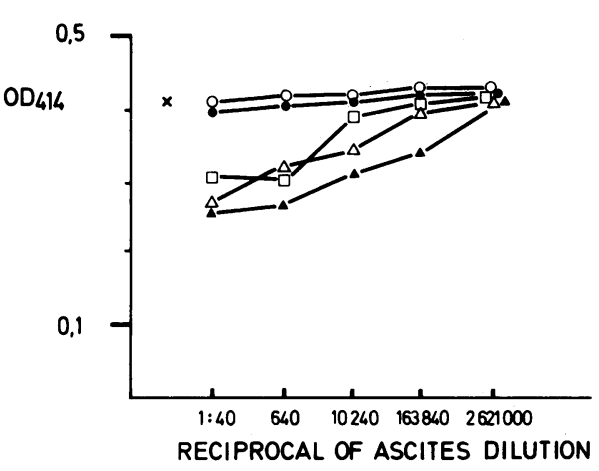

Figure 5. Inhibition of binding of a C2D guinea pig serum to $\mathrm{C} 3 \mathrm{~b}$ by different mouse monoclonal antibodies to guinea pig C3b (all $\gamma 1$ subclass). ( $x$ ) Inhibition without ascites; (0) control ascites; ( $\bullet$ ) mono-

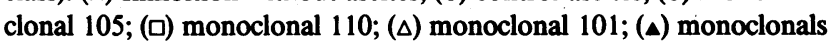
110 and 101 together.

Interassay correlation in C-deficient guinea pig sera. No correlation was found between the results of the different guinea pig-anti-mouse $\gamma \mathrm{i}, \gamma 2$, or $\gamma 3$ assays, because most animals were only positive in one of these assays (data not given).

When comparing serum IgM levels with levels of guinea pig-anti-mouse immunoglobulins or IgM-RF, the correlation was significant, albeit weak; e.g., $r=0.298$ and $P=0.001$ for IgM-RF. In addition, serum IgM levels correlated well with levels of IgM antibodies to DNP, as shown in Fig. 6.

Influence of sex and age. Matching the C-deficient guinea pigs for sex revealed no difference in any of the assays described ábove. When young C-deficient animals (between 2 wk and 5 mo of age) were examined, they clearly had elevated IgM and IgM anti-DNP antibody levels (Fig. 7; for comparison see Fig. 1 and 2). Both parameters exclusively reflect antibodies of childish origin and transferred maternal antibodies are therefore excluded.

With respect to the presence of IgM-RF, it was interesting to observe that a tendency of the adult guinea pig, namely the more common presence of IgM-RF in the C4D-GP vs. the C2DGP ( $38 \%$ vs. $22.4 \%$; see Fig. 4$)$ was even more pronounced in

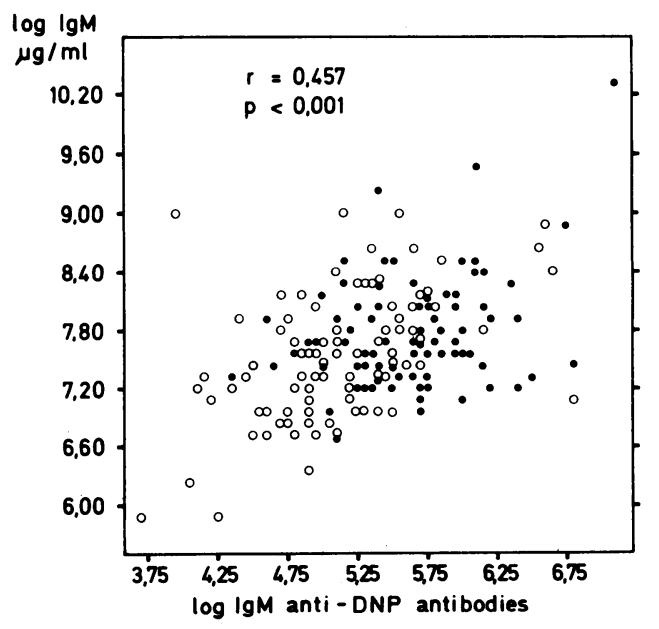

Figure 6. Correlation of serum IgM levels to IgM anti-DNP activity in sera of C-deficient guinea pigs $(n=182)$; (0) C2D-GP $(n=91)$; (๑) C4D GP $(n=91)$. 


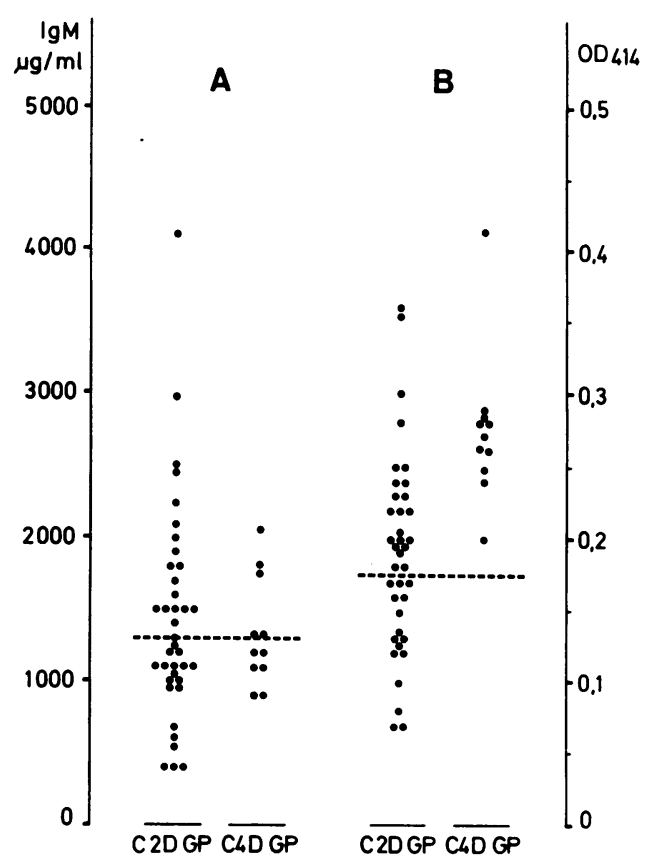

Figure 7. Serum IgM concentrations (in $\mu \mathrm{g} / \mathrm{ml}, A$ ) and IgM antibodies to DNP (expressed as OD, $B$ ) in sera of young ( $>2 \mathrm{wk}<5 \mathrm{mo}$ ) C2DGP $(n=38)$ and C4D-GP $(n=11)$. The dotted line indicates each normal mean $+2 \mathrm{SD}$, respectively.

young animals: only 1 of 38 C2D-GP (2.6\%) had elevated levels of IgM-RF compared to 6 of 11 C4D-GP (55\%). The seemingly more common presence of IgM-RF in young C4D-GP in comparison to their adult counterparts is due to the small number of young animals available and statistically not significant.

\section{Discussion}

The etiology and many of the details of pathogenesis of SLE and related syndromes have not been elucidated, but it is well established that autoimmune diseases frequently are associated with multiple autoantibodies (for review, 4). It is known, however, that humans, genetically deficient in components of the classical $\mathrm{C}$ pathway, are prone to immune complex diseases, particularly juvenile SLE (1-3).

The experiments described here show that guinea pigs, genetically deficient in either $\mathrm{C} 2$ or $\mathrm{C} 4$, have unusual antibodies such as rheumatoid factors in their sera, although they appear healthy. By necessity this phenomenon was limited to only a subpopulation of all C-deficient animals tested, e.g., 22.4\% of the C2D-GP and 38.4\% of the C4D-GP had levels of IgM-RF exceeding normal mean $+2 \mathrm{SD}$, compared with $0.8 \%$ for control animals.

Taking together the results of the RF assays for heterologous mouse gamma-globulin of $\gamma 1, \gamma 3$, or $\gamma 2$ a subclass, $25.7 \%$ of the C-deficient guinea pigs vs. $6.5 \%$ of the control animals had antibodies against heterologous mouse gamma-globulin. The RF assays specific for certain subclasses did not correlate well with one another, i.e., most C-deficient guinea pigs were positive in only one of these assays. We therefore assume that by further extending the number of antigens tested, the absolute number of C-deficient guinea pigs showing autoantibodies will increase.

Some C-deficient guinea pigs had high titers of antibodies against $\mathrm{C} 3 \mathrm{~b}$ but not native $\mathrm{C} 3$, which is of particular interest, in that it is known that some SLE patients have autoantibodies against the classical pathway C3 convertase (25). However, the difference in incidence to normal animals did not prove to be significant.

The results of our solid-phase C3 immunoassay for detection of circulating immune complexes were impaired because guinea pig antibodies against mouse $\gamma 1$-globulin interfered with this assay. In preliminary attempts to demonstrate deposited immune complexes in kidneys, the results were equivocal. In fact, normal guinea pigs spontaneously showed deposits of IgG and $C$ in their kidneys, which is in accordance with observations reported previously (26).

A further characteristic of both C-deficient strains was a spontaneous increase of serum IgM and anti-DNP antibodies. Both parameters correlated well, signifying a more active polyclonal antibody synthesis than in the normal strains. These results agree with several observations made in human and murine SLE. First of all, peripheral blood lymphocytes from patients with SLE show increased levels of anti-hapten plaque forming cells (27) and increased in vitro spontaneous immunoglobulin synthesis (28). Secondly, a general feature of all murine SLE models (14) is hypergammaglobulinemia and increased antihapten antibody levels (13). Interestingly, experimentally induced polyclonal B cell stimulation in mice in vivo also led to elevated levels of IgM-RF, anti-DNP antibodies, anti-DNA antibodies (29-31), and other autoantibodies (32), as well as to hypergammaglobulinemia, whereby elevation of IgM was a general phenomenon, but elevation of IgG dependent on the stimulus used for polyclonal activation (33). However, we could only show a weak correlation between levels of serum IgM and IgMRF in C-deficient guinea pigs. This is in accordance with observations made in murine SLE strains, where hypergammaglobulinemia and increased anti-hapten antibody levels are a general phenomenon, but expression of the different autoantibodies is markedly strain-dependent and only weakly correlates with serum IgM levels (34).

Several points, however, indicate that these C-deficient guinea pigs are a distinct entity: in contrast to murine SLE models there is no sex dependency and even young GP show these phenomena. Most remarkable are the normal levels of serum IgG. In this regard, it is interesting that the onset of clinical disease in various murine SLE strains is often at a time, when hypergammaglobulinemia and autoantibodies switch from IgM to IgG $(35,36)$.

It is noteworthy that the serologic abnormalities reported here are persistent: longitudinal studies for at least 3 mo have shown that they were detectable during the whole period (data not given).

Several mechanisms have been proposed to explain the association of $\mathrm{C}$ deficiency and autoimmune disease in humans: one is based on the observation that $\mathrm{C}$ may directly neutralize virus $(37,38)$. Therefore, $C$ deficiency may lead to defective antigen clearance or make the individual suspectible to certain infectious agents, which in turn leads to the development of immune complex disease. Another is based on the finding that prevention of immune complex precipitation or solubilization of immune aggregates in vitro requires C (39-42). It was hypothesized that $\mathrm{C}$ deficiencies of the early components lead to ineffective clearance of immune complexes in vivo and therefore to immune complex disease. Immune complexes by themselves have been shown in vitro to stimulate $B$ cells in a polyclonal fashion (43-46), which may explain the development of auto- 
antibodies; however, this has been refuted by others $(47,48)$. On the other hand, it has been suggested that the genes for $\mathrm{C} 2$ or C4, which are located within the MHC complex $(49,50)$, may be linked to suspectibility genes for such diseases (51) genes which may or may not be related to the presumed human immune response genes. Therefore deficiency in C2 or C4 may only function as a marker without a causal role for the deficiency state itself. This explanation seems a less likely possibility, since although the $\mathrm{C} 2 \mathrm{Q} 0$ allele is often linked with the same extended MHC haplotype, this does not hold true for C4 deficiency (1). In addition deficiencies in $\mathrm{Cl}$ or its subunits-their genes are probably not MHC-linked-are also associated with IC-disease.

Regarding the question of linkage it is noteworthy that C2and C4-deficient guinea pigs differ in their MHC alleles $(15,17)$. It is important to note that the strain 13 , which has the same MHC alleles as the C4D strain but normal C4 levels, was completely normal in all assays tested. These observations strengthen the hypothesis that $C$ deficiency itself is responsible for the association of $\mathrm{C}$ deficiency and autoimmune disease in humans.

Recently, C2D-GP and C4D-GP were shown to have an impaired humoral immune response to a $T$ cell-dependent antigen (5). We therefore proposed that $\mathrm{C} 3$ contributes to reaching a normal humoral immune response in guinea pigs. Our findings here support the concept that the $\mathrm{C}$ system might have a regulatory role in cells associated with the production of immunoglobulins. With regard to $T$ cell functions, earlier observations have failed to show an influence of $\mathrm{C} 4$ deficiency in guinea pigs: C4D-GP respond well to specific antigen or mitogen-induced proliferation in vitro (52) and induction of immunologic tolerance appeared normal (53).

Independent of the mechanism, our results suggest that $\mathrm{C} 2$ and C4-deficient guinea pigs may serve as an experimental model to study the mechanism of the association of $\mathrm{C}$ deficiency and autoimmune disease in humans.

\section{Acknowledgments}

The authors thank Susanne Metzger for excellent technical assistance, Dr. Hommel from the Institute for Medical Statistics, Mainz, for help in statistical analysis, and Dr. D. R. Schultz (Miami, FL) for helpful discussions.

This work was supported by grants from the Deutsche Forschungsgemeinschaft, SFB 311, Mainz, Federal Republic of Germany.

\section{References}

1. Alper, C. A., and F. S. Rosen. 1984. Inherited deficiencies of complement proteins in man. Springer Semin. Immunpathol. 7:251-261.

2. Agnello, V. 1978. Complement deficiency states. Medicine (Baltimore). 57:1-23.

3. Lachmann, P. J., and F. S. Rosen. 1978. Genetic defects of complement in man. Springer Semin. Immunpathol. 1:339-353.

4. Smith, H. R., and A. D. Steinberg. 1983. Autoimmunity-a perspective. Annu. Rev. Immunol. 1:175-210.

5. Böttger, E. C., T. Hoffmann, U. Hadding, and D. Bitter-Suermann. 1985. Influence of genetically inherited complement deficiencies on humoral immune response in guinea pigs. J. Immunol. 135:4100-4107.

6. Ellman, L., I. Green, F. Judge, and M. M. Frank. 1971. In vivo studies in C4-deficient guinea pigs. J. Exp. Med. 134:162-175.

7. Ochs, H. D., R. J. Wedgwood, M. M. Frank, S. R. Heller, and S. W. Hosea. 1983. The role of complement in induction of antibody responses. Clin. Exp. Immunol. 53:208-216.

8. Kunkel, H. G., H. M. Müller-Eberhard, H. H. Fudenberg, and
T. B. Tomasi. 1961. $\gamma$-Globulin complexes in rheumatoid arthritis and certain other conditions. J. Clin. Invest. 40:117-129.

9. Kunkel, H. G., and E. M. Tane. 1964. Autoantibodies and disease. Adv. Immunol. 4:351-395.

10. Torrigiani, G., and I. Roitt. 1967. Antiglobulin factors in sera from patients with rheumatoid arthritis and normal subjects. Ann. Rheum. Dis. 26:334-340.

11. Panush, S., N. Bianco, and P. Schur. 1971. Serum and synovial fluid IgG, IgA, and IgM anti- $\gamma$-globulins in rheumatoid arthritis. Arthritis Rheum. 14:737-747.

12. Natvig, J., P. Gaarder, and M. Turner. 1972. IgG antigens of the $\mathrm{C}_{2} 2$ and $\mathrm{C}_{\boldsymbol{1}} 3$ and homology regions interacting with rheumatoid factors. Clin. Exp. Immunol. 12:177-184.

13. Izui, S., P. J. McConahey, and F. J. Dixon. 1978. Increased spontaneous polyclonal activation of B lymphocytes in mice with spontaneous autoimmune disease. J. Immunol. 121:2213-2219.

14. Theofilopoulos, A. N., and F. J. Dixon. 1985. Murine models of systemic lupus erythematosus. Adv. Immunol. 37:269-390.

15. Bitter-Suermann, D., T. Hoffmann, R. Burger, and U. Hadding. 1981. Linkage of total deficiency of the second component of the complement system and of genetic C2-polymorphism to the major histocompatibility complex of the guinea pig. J. Immunol. 127:608-612.

16. Gaither, T. A., D. W. Alking, and M. M. Frank. 1974. A new one-step method for the functional assay of the fourth component of human and guinea pig complement. J. Immunol. 113:574-583.

17. Bitter-Suermann, D. 1979. Complement factors: guinea pig. In Inbred and Genetically Defined Strains of Laboratory Animals. Part 2, Data Book of the Federation of American Societies for Experimental Biology. Bethesda, MD. S 539-543.

18. Aguado, M. T., J. D. Lambris, G. C. Tsokos, R. Burger, D. BitterSuermann, J. D. Tamerius, F. J. Dixon, and A. N. Theofilopoulos. 1985. Monoclonal antibodies against C3 neoantigens for detection of immune complexes and complement activation. J. Clin. Invest. 76:1418-1426.

19. Burger, R., U. Deubel, U. Hadding, and D. Bitter-Suermann. 1982. Identification of functionally relevant determinants on the complement component C3 with monoclonal antibodies. J. Immunol. 129: 2042-2050.

20. Bradford, M. 1976. A rapid and sensitive method for the quantitation of microgram quantities of protein, utilizing the principle of protein-dye binding. Anal. Biochem. 72:248-254.

21. Bitter-Suermann, D., H. Peters, M. Jürs, R. Nehrbass, M. Montenegro, and K. Timmis. 1984. Monoclonal antibody detection of IncF group plasmid-encoded TraT protein in clinical isolates of Escherichia coli. Infect. Immun. 46:308-313.

22. Lindmark, R., K. Thoren-Tolling, and J. Sjöquist. 1983. Binding of immunoglobulins to Protein-A and immunoglobulin levels in mammalian sera. J. Immunol. Methods 62:1-13.

23. Furuichi, K., M. Kato, T. Nakamura, and J. Koyama. 1974. Preferential production of IgG2-anti-hapten antibody in guinea pigs immunized with 2,4-dinitrophenylated liposaccharides of Escherichia coli. J. Biochem. 76:1147-1149.

24. Ricardo, M. J., Jr. 1979. Properties of Immunoglobulins: guinea pig. In Inbred and Genetically Defined Strains of Laboratory Animals. Part 2. Data Book of the Federation of American Societies for Experimental Biology. Bethesda, MD. S 536-539.

25. Daha, M., H. Hazevoet, and L. Van Es. 1984. Heterogeneity, polypeptide chain composition and antigenic reactivity of autoantibodies $(\mathrm{F}-\overline{4} \overline{2})$ that are directed against the classical pathway $\mathrm{C} 3$ convertase of complement and isolated from sera of patients with systemic lupus erythematosus. Clin. Exp. Immunol. 56:614-620.

26. Steblay, R., and U. Rudofsky. 1971. Spontaneous renal lesions and glomerular deposits of IgG and complement in guinea pigs. J. Immunol. 107:1192-1196.

27. Budmann, D. R., E. B. Merchant, A. D. Steinberg, B. Doft, M. E. Gershwin, E. Lizzio, and J. P. Reeves. 1977. Increased spontaneous activity of antibody-forming cells in the peripheral blood of patients with active SLE. Arthritis Rheum. 20:829-833.

28. Kallenberg, C. G. M., P. C. Limburg, C. van Slochteren, F. J. 
van der Woude, and T. H. The. 1983. B-cell activity in systemic lupus erythematosus: depressed in vivo humoral immune response to a primary antigen (haemocyanin) and increased in vitro spontaneous immunoglobulin synthesis. Clin. Exp. Immunol. 53:371-383.

29. Izui, S., N. Zaldivar, I. Scher, and P. H. Lambert. 1977. Mechanism for induction of anti-DNA antibodies by bacterial lipopolysaccharides in mice. I. Anti-DNA induction by LPS without significant release of DNA in circulating blood. J. Immunol. 119:2151-2156.

30. Izui, S., T. Kobayakawa, M. J. Zryd, J. Louis, and P. H. Lambert. 1977. Mechanism for induction of anti-DNA antibodies by bacterial lipopolysaccharides in mice. II. Correlation between anti-DNA induction and polyclonal antibody formation by various polyclonal B lymphocyte activators. J. Immunol. 119:2157-2162.

31. Izui, S., R. A. Eisenberg, and F. J. Dixon. 1979. IgM rheumatoid factors in mice injected with bacterial lipopolysaccharides. J. Immunol. 122:2096-2102.

32. Primi, D., L. Hammarström, I. E. Smith, and G. Möller. 1977. Characterization of self-reactive B cells by polyclonal B cell activators. J. Exp. Med. 145:21-30.

33. Izui, S., R. A. Eisenberg, and F. J. Dixon. 1981. Subclass restricted IgG polyclonal antibody protection in mice injected with lipid A-rich lipopolysaccharides. J. Exp. Med. 153:324-338.

34. Andrews, B. S., R. A. Eisenberg, A. N. Theofilopoulos, S. Izui, C. B. Wilson, P. J. McConahey, E. D. Murphy, J. B. Roths, and F. J. Dixon. 1978. Spontaneous murine lupus-like syndromes. J. Exp. Med. 148:1198-1215.

35. Theofilopoulos, A. N., D. L. Shawler, R. A. Eisenberg, and F. J. Dixon. 1980. Splenic immunoglobulin-secreting cells and their regulation in autoimmune mice. J. Exp. Med. 151:446-466.

36. Papoian, R., R. Pillarisetty, and N. Talal. 1977. Immunological regulation of spontaneous antibodies to DNA and RNA. Immunology. 32:75-79.

37. Daniels, C., T. Borsos, H. Rapp, R. Synderman, and A. Notkins. 1969. Neutralization of sensitized virus by purified compounds of complement. Proc. Natl. Acad. Sci. USA. 65:528-535.

38. Cooper, N., C. Jensen, M. Welsh, and A. Oldstone. 1976. Lysis of RNA tumor viruses by human serum: direct antibody independent triggering of the classical complement pathway. J. Exp. Med. 144:970984.

39. Miller, G. W., and V. Nussenzweig. 1975. A new complement function: solubilization of antigenic antibody aggregates. Proc. Natl. Acad. Sci. USA. 72:418-422.
40. Takahashi, M., S. Takahashi, V. Brade, and V. Nussenzweig. 1978. Requirements for the solubilization of immune aggregates by complement: the role of the classical pathway. J. Clin. Invest. 62:349358.

41. Schifferli, J. A., and D. K. Peters. 1983. Complement, the immune-complex lattice, and the pathophysiology of complement-deficiency syndromes. Lancet. ii:957-959.

42. Naama, J. K., E. Holme, E. Hamilton, and K. Whaley. 1985. Prevention of immune precipitation by purified components of the alternative pathway. Clin. Exp. Immunol. 60:169-177.

43. Morgan, E. L., and W. O. Weigle. 1983. Polyclonal activation of murine B lymphocytes by immune complexes. J. Immunol. 130:10661070.

44. Bloch-Stacher, N., K. Hirschhorn, and J. W. Uhr. 1968. The response of lymphocytes from nonimmunized humans to antigen-antibody complexes. Clin. Exp. Immunol. 3:889-899.

45. Soderberg, L. S. F., and A. H. Coons. 1978. Complement-dependent stimulation of normal lymphocytes by immune complexes. $J$. Immunol. 120:806-811.

46. Hobbs, M. V., E. L. Morgan, N. L. Baker, and W. O. Weigle. 1985. Regulation of antibody responses by rheumatoid factor. I. Polyclonal activation of human B cells by rheumatoid factor containing preparations from seropositive plasma. J. Immunol. 134:223-229.

47. LaVia, M. F., and D. S. LaVia. 1978. Studies on Fc-receptor function. I. IgM-mediated inhibition of B lymphocyte activation by Tdependent and T-independent antigens. Cell. Immunol. 39:297-306.

48. Ryan, J. L., and P. A. Henkart. 1976. Fc receptor-mediated inhibition of murine B lymphocyte activation. J. Exp. Med. 144:768-775.

49. Colten, H. R. 1983. The complement genes. Immunol. Today. 4:151-154.

50. Carroll, M. C., R. D. Campbell, D. R. Bentley, and R. R. Porter. 1984. A molecular map of the human MHC-complex class III region linking complement genes C4, C2, and Factor B. Nature (Lond.). 307: 237-241.

51. Schur, P. H. 1982. Complement and lupus erythematosus. Arthritis Rheum. 25:793-798.

52. Burger, R., and E. M. Shevach. 1979. Evaluation of the role of $\mathrm{C} 4$ in the cellular immune response in vitro. J. Immunol. 122:23882394.

53. Cohen, B. E., I. Green, and J. Davie. 1973. Immunologic tolerance in C4-deficient guinea pigs. J. Immunol. 110:608-611. 